\title{
Repertorio de Medicina y Cirugía
}

\section{Editorial}

\section{Raúl Barrios Angulo}

Marzo 20 de 1930

† Octubre 25 de 2018

Dario Cadena Rey MD $^{\mathrm{a}}$

${ }^{a}$ Director de Repertorio de Medicina y Cirugia, Bogotá DC, Colombia.

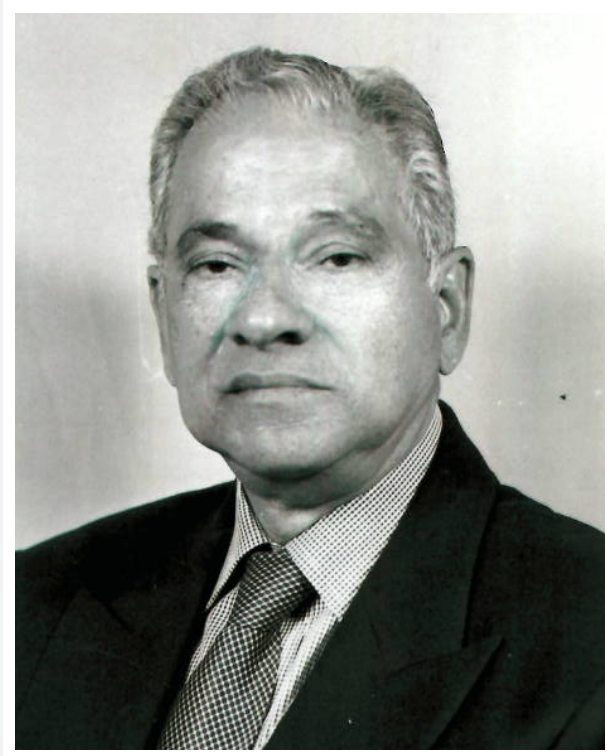

La Sociedad de Cirugía de Cirugía de Bogotá está de luto por el fallecimiento del exdirector del Hospital de San José, doctor Raúl Barrios Angulo, y quiere rendirle un homenaje al evocar en estas páginas editoriales de Repertorio de Medicina y Cirugía el cariño y el inmenso afecto que profesó por nuestras instituciones.
Nació en San Juan Nepomuceno, Bolívar, en el hogar del muy querido médico cartagenero Hernando Barrios Herrera y doña Lorencita Angulo. Muy pronto se trasladaron a Cartagena donde cursó sus estudios escolares y universitarios, graduándose como Médico y Cirujano en la Universidad de Cartagena en 1958. Al poco tiempo partió para Estados Unidos e ingresó a la Universidad de Tulane en New Orleans donde se especializó en fisiología y medicina interna. Allí conoció a quien sería su esposa Mercedes, quien también hacía su posgrado en la misma universidad, hija de Mercedes Rey Rojas y de Dario Cadena Camacho, profesor de anatomía y exdecano de la Facultad de Medicina de la Universidad Nacional, su alma mater, y profesor y gestor de la reapertura de la Facultad de Medicina del Colegio Mayor de Nuestra Señora del Rosario.

El Dr. Barrios regresó a Cartagena donde ocupó importantes posiciones en el Hospital Naval, el Hospital de Manga y el Terminal marítimo. Ya casado se trasladó a Bogotá para ocupar numerosos cargos médicos y administrativos en el Seguro Social, en la Clínica de Urgencias y en la San Pedro Claver. En 1968 realizó en Santiago de Chile estudios de economía y planificación de organismos de salud. Estos conocimientos lo llevaron a la alta dirección del entonces Instituto Colombiano de Seguros Sociales (ICSS) como Coordinador de Servicios Médicos, Jefe del Departamento Médico en la Caja Seccional de Cundinamarca (1967-1975), asesor de la Dirección General, Médico Jefe de Planeación, Director de la Oficina

INFORMACIÓN DEL ARTÍCULO

Historia del artículo:

Fecha recibido: enero 24 de 2019 Fecha aceptado: enero 31 de 2019
Autor para correspondencia. Dr. Dario Cadena Rey proyectos.especiales@fucsalud.edu.co
DOI

10.31260/RepertMedCir.v28.n1.2019.885 
de Organización y Desarrollo a nivel nacional (1976-1978) y Coordinador Médico del ICSS en el Hospital de San José (1978-1986).

Al retirarse del ICSS se vinculó muy estrechamente con el Hospital de San José, ingresó como Miembro de Número de la Sociedad de Cirugía de Bogotá en 1989 y desempeñó la subdirección médica de 1989 a 1993.

Fue jefe del Departamento de Servicios Ambulatorios y Director del Hospital de San José de 1997 a 2001. Durante su gestión debió enfrentar la crisis causada por el retiro del ICSS del hospital, iniciando la prestación de servicios a las incipientes Empresas Prestadoras de Servicios de Salud que surgieron como consecuencia de la ley 100 de 1993, al liquidar el instituto de Seguro Social y dando origen al modelo de atención en salud que hoy, con todas sus modificaciones, sigue rigiendo en el país.

Fue con los doctores Raúl Barrios, Luis Carlos Taborda y la administración del hospital que planeamos e iniciamos la remodelación de los pabellones Uricoechea, Machado y Santa Inés, en la esquina suroccidental del edificio, para dotar a la institución de la consulta externa y la unidad renal que hoy muestra con orgullo el hospital. Su gestión fue dinámica, progresista e innovadora, guardando el respeto y el agradecimiento al importante recurso humano. Siempre lo tendremos en la mente por su ánimo conciliador, alegre y gentil que lo caracterizó.

Fue un ejemplar miembro de familia, solidario, leal, dispuesto a brindar su apoyo en momentos difíciles. Admirador del arte en todas sus expresiones, el teatro, la ópera de la cual era gran conocedor, la música y el canto del cual fue buen intérprete en especial de las composiciones de Agustín Lara y los ritmos gitanos de su querida Andalucía.

Perteneció a numerosas sociedades científicas y como Director fue un pilar definitivo para la creación de la Facultad de Medicina de la Fundación Universitaria de Ciencias de la Salud, de la cual fue profesor. La Sociedad de Cirugía lo honró como Miembro Honorario en febrero de 2009.

Un gran recuerdo nos lega Raúl como colega, colaborador, ejecutivo, pero sobretodo como una verdadero y gran amigo. La comunidad de la Sociedad de Cirugía de Bogotá - Hospital de San José expresa sus sentimientos de solidaridad a su esposa Mercedes, a sus hijos Rocío médica psiquiatra que en la actualidad ejerce en Nueva York, a Felipe exitoso abogado que nos ha brindado sus conocimientos jurídicos al Hospital y a la FUCS, y a Maria José brillante y reconocida psicóloga, extensivo a todos sus familiares y en especial a sus nietos que tanto amó. 